Jurnal

Manajemen Kesehatan Indonesia

Volume 6

Nomor 1

April 2018

\title{
Analisis Penerimaan Sistem Informasi Manajemen Rumah Sakit menggunakan Technology Acceptance Model di RSUD Kajen Kabupaten Pekalongan
}

\author{
Imaniar Sevtiyani*, Eko Sediyono**, Sri Achadi Nugraheni*** \\ *Univesitas Jendral Achmad Yani Yogyakarta \\ **Universitas Kristen Setya Wacana Salatiga \\ ***Fakultas Kesehatan Masyarakat, Universitas Diponegoro, Semarang \\ Universitas Diponegoro \\ Email: isevtiyani@gmail.com
}

\section{ABSTRACT}

The implementation of hospital management information system in Indonesia is regulated in Permenkes No.1171 year 2011 and Law No.14 year 2008. One of the most important factor in hospital management information system success is driven by user readiness. RSUD Kajen Pekalongan Regency has implemented hospital management information system since 2015, but it has not run optimally yet. The purpose of this study is to analyze technology hospital management information system in RSUD Kajen used Technology Acceptance Model (TAM) method.

This research used a correlational quantitative research with cross sectional approach. The respondents were 44 staff of RSUD Kajen which using the hospital management information system in RSUD Kajen Pekalongan Regency due accordance with the criteria determined by the census method. The data were collected by questionnaire. Data analysis was performed using Structural Equation Modeling (SEM) with smartPLS software.
The result showed $63.8 \%$ that subjective norm have direct and significant influence to the intention to use hospital management information system RSUD Kajen Pekalongan Regency $(T=3,275)$, computer self efficacy directly and significant to perceived ease of use hospital information system RSUD Kajen Pekalongan Regency $(T=7,857)$, perceived ease of use are related directly and significantly perceived usefulness of hospital management information system RSUD Kajen Pekalongan Regency with the perceived of usefulness $(T=3.227)$ and intention to use hospital management information system RSUD Kajen Pekalongan Regency $(T=2,034)$. Recommendation of the result is making the policy of hospital management information system implementation usage of RSUD Kajen, the improvement of staff knowledge, skill and the periodic monitoring and evaluation hospital management information system RSUD Kajen Pekalongan Regency usage.

Keywords : HIS, Technology Acceptance Model, user acceptance. 
dengan menggunakan Technology Acceptance Model.

\section{PENDAHULUAN}

Setiap rumah sakit dalam menjalankan fungsinya wajib melakukan pengelolaan data meliputi pencatatan dan pelaporan terkait semua kegiatan pelayanan kesehatan yang dilakukan, hal tersebut sesuai dengan ketentuan pasal 52 UU No.44 tahun 2009. ${ }^{1}$

Pengelolaan data merupakan bagian penting dalan suatu sistem informasi yang ada di rumah sakit. Sistem Informasi Rumah Sakit (SIRS) adalah sistem yang berkaitan dengan pengelolaan data di rumah sakit yang dapat mengintegrasikan sistem informasi dari berbagai sub sistem dan dapat mengolah data yang berfungsi dalam proses pengambilan keputusan. Permenkes No.1171 tahun 2011 mengatur bahwa seluruh rumah sakit di Indonesia wajib menyelenggarakan SIM RS. ${ }^{2}$

Kesiapan pengguna merupakan faktor penting dalam kesuksesan implementasi SIRS. Kesiapan pengguna dipengaruhi oleh sikap dan perilaku pengguna dalam memanfaatkan SIRS tersebut. Technology Acceptance Model (TAM) merupakan konsep yang dapat menjelaskan perilaku user terhadap penerimaan suatu sistem informasi baru.

Sistem Informasi Manajemen (SIM) RSUD Kajen yang diimplementasikan saat ini pemanfaatannya masih kurang optimal. Kurang optimalnya pemanfaatan SIM RS berdampak pada informasi yang dihasilkan menjadi tidak valid, tidak akurat dan tidak tepat waktu sehingga keputusan yang diambil menjadi tidak tepat.

Penelitian ini bertujuan untuk menganalisis penerimaan implementasi SIM RSUD Kajen Kabupaten Pekalongan

\section{METODE PENELITIAN}

Penelitian ini merupakan penelitian kuantitatif dengan pendekatan cross sectional). Pengumpulan data primer menggunakan kuesioner terstruktur. Sampel penelitian ini adalah staff yang menggunakan dan berhubungan dengan SIM RSUD Kajen yang berjumlah 44 orang yang ditentukan secara sensus/sampel jenuh. Analisis data menggunakan SEM PLS dengan software smart PLS.

\section{HASIL DAN PEMBAHASAN \\ Hasil Penelitian}

Sebagian besar responden berumur 3640 tahun dengan pendidikan D-III dan dengan rata-rata lama bekerja 11-15 tahun.

Kesesuaian SIM RSUD Kajen dengan kinerja responden sudah baik (90\%). Norma subjektif terkait implementasi SIM RS di RSUD Kajen tinggi (52,3\%). Keyakinan diri responden terkait penggunaan SIM RSUD Kajen baik (63,6\%). Persepsi responden terhadap manfaat SIM RSUD Kajen baik $(81,8 \%)$. Persepsi responden terhadap kemudahan penggunaan SIM RSUD Kajen baik $(52,3 \%)$. Niat responden untuk menggunakan SIM RSUD Kajen tinggi (84,1\%). Perilaku responden terkait penggunaan SIM RSUD Kajen baik (50\%).

\section{Uji Model Pengukuran (outer model)}

Uji model pengukuran dilakukan dengan menguji validitas dan reliabilitas indikator pada setiap variabel. ${ }^{3}$ Indikator dikatakan valid bila memiliki nilai loading factor dan nilai average variance extracted (AVE) $>0,50$ serta dikatakan reliabel apabila memiliki nilai cronbach's alpha 
$>0,60$. Hasil pengukuran outer model dapat dilihat pada tabel 1 .

Tabel 1 menunjukkan berdasarkan nilai loading factor terdapat indikator yang tidak valid, indikator yang tidak valid dikeluarkan lalu kemudian dilakukan uji reliabilitas dengan melihat nilai cronbach's alpha. Pada penelitian ini nilai cronbach's alpha $>0,60$ sehingga semua variabel penelitian reliabel.

1 . Undang-Undang Nomor 44 tahun 2009 tentang Rumah Sakit

2 . Peraturan Menteri Kesehatan Republik Indonesia Nomor 1171/ MENKES/ PER/ VI/ 2011 tentang Sistem Informasi Rumah Sakit.

3 . Nurjazuli. Paradigma Baru dalam Analisis Data Penelitian: Structural Equation Modeling dengan Visual Partial Least Square (VPLS). Semarang: Badan Penerbit Universitas Diponegoro; 2012.

Tabel 1. Outer Model

\begin{tabular}{lccc}
\hline \multicolumn{1}{c}{ Variabel } & Loading Factor & AVE & $\begin{array}{c}\text { Cronbach's } \\
\text { Alpha }\end{array}$ \\
\hline Kesesuaian pekerjaan (REL) & No.2,3,4,6,9 & 0,500 & 0,825 \\
Norma subjektif(SN) & No.4,5,6 & 0,815 & 0,929 \\
Keyakinan diri pengguna (SE) & No.2,3,4,5 & 0,513 & 0,600 \\
Persepsi manfaat (PU) & Seluruhnya & 0,613 & 0,916 \\
Persepsi kemudahan penggunaan (PEOU) & No.1,2,3,4,7,8,9 & 0,500 & 0,866 \\
Niat menggunakan (IU) & Seluruhnya & 0,529 & 0,870 \\
Perilaku penggunaan (UB) & Seluruhnya & 0,535 & 0,846 \\
\hline
\end{tabular}

Uji Model Struktural (inner model)

Uji model struktural dilakukan dengan melihat nilai koefisien jalur (path analysis) dan nilai signifikasi dengan uji T. Hasil pengukuran inner model dapat dilihat pada gambar 1 dan tabel 2. 


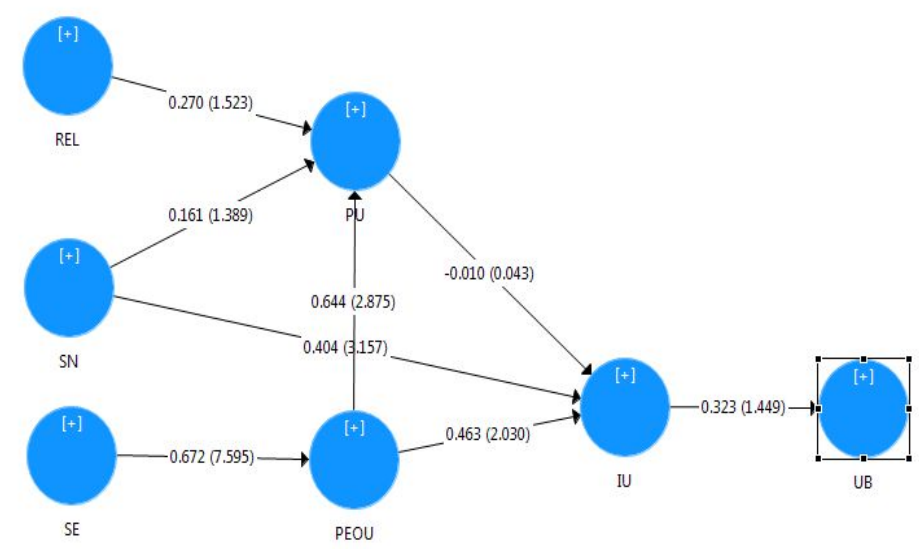

Gambar 1 Inner model nilai signifikansi uji $T$ Tabel 2. Inner Model

\begin{tabular}{lccc}
\hline \multicolumn{1}{c}{ Hipotesis } & Koef regresi $(\mathrm{r})$ & Nilai $\mathrm{T}$ & Sig $(\mathrm{p})$ \\
\hline $\mathrm{REL} \rightarrow \mathrm{PU}$ & 0,270 & 1,522 & 0,129 \\
$\mathrm{SN} \rightarrow$ PU & 0,161 & 1,325 & 0,186 \\
$\mathrm{SN} \rightarrow \mathrm{IU}$ & 0,404 & 3,275 & 0,001 \\
$\mathrm{SE} \rightarrow$ PEOU & 0,672 & 7,857 & 0,000 \\
$\mathrm{PEOU} \rightarrow$ PU & 0,644 & 3,227 & 0,001 \\
$\mathrm{PU} \rightarrow \mathrm{IU}$ & $-0,010$ & 0,045 & 0,965 \\
$\mathrm{PEOU} \rightarrow \mathrm{IU}$ & 0,463 & 2,034 & 0,042 \\
\hline
\end{tabular}

Pengaruh Kesesuaian Pekerjaan terhadap Persepsi Manfaat SIM RSUD Kajen

Hasil uji $\mathrm{T}$ variabel kesesuaian pekerjaan terhadap variabel persepsi manfaat adalah sebesar 1,522 $(\mathrm{T}<1,96)$, hal tesebut berarti tidak terdapat pengaruh yang signifikan antara kesesuaian SIM RSUD Kajen dengan pekerjaan responden terhadap persepsi manfaat SIM RSUD Kajen.

\section{Pengaruh Norma Subjektif terhadap} Persepsi Manfaat SIM RSUD Kajen

Hasil uji $\mathrm{T}$ variabel norma subjektif terhadap variabel persepsi manfaat adalah sebesar 1,325 $(\mathrm{T}<1,96)$, hal tesebut berarti tidak terdapat pengaruh yang signifikan antara norma subjektif terhadap persepsi manfaat SIM RSUD Kajen.

Pengaruh Norma Subjektif terhadap Niat Menggunakan SIM RSUD Kajen

Hasil uji $\mathrm{T}$ variabel norma subjektif terhadap variabel niat menggunakan adalah sebesar 3,275 (T>1,96), hal tesebut berarti terdapat pengaruh yang signifikan antara norma subjektif terhadap niat menggunakan SIM RSUD Kajen. Semakin tinggi norma subjektif di lingkungan RSUD Kajen maka semakin tinggi pula niat staff RSUD Kajen untuk menggunakan SIM RSUD Kajen ( $r=0,404)$. Pengaruh Keyakinan Diri terhadap Persepsi Kemudahan Penggunan SIM RSUD Kajen

Hasil uji $\mathrm{T}$ variabel keyakinan diri pengguna terhadap variabel persepsi kemudahan penggunaan adalah sebesar 7,857 ( $\mathrm{T}>1,96)$, hal tesebut berarti terdapat pengaruh yang signifikan antara keyakinan diri staff RSUD Kajen terhadap persepsi kemudahan penggunaan SIM RSUD Kajen. Semakin tinggi keyakinan diri staff maka semakin tinggi pula persepsi staff terkait kemudahan penggunaan SIM RSUD Kajen $(\mathrm{r}=0,672)$.

Pengaruh Persepsi Kemudahan Penggunan terhadap Persepsi Manfaat SIM RSUD Kajen 
Hasil uji T variabel persepsi kemudahan penggunaan terhadap variabel persepsi manfaat adalah sebesar 3,227 (T>1,96), hal tesebut berarti terdapat pengaruh yang signifikan antara persepsi kemudahan penggunaan terhadap persepsi manfaat SIM RSUD Kajen. Semakin tinggi persespsi staff terkait kemudahan penggunaan maka semakin tinggi pula persi staff terkait manfaat SIM RSUD Kajen $(r=0,644)$.

\section{Pengaruh Persepsi Manfaat terhadap} Niat Menggunakan SIM RSUD Kajen

Hasil uji $\mathrm{T}$ variabel persepsi manfaat terhadap variabel niat menggunakan adalah sebesar 0,045 $(\mathrm{T}<1,96)$, hal tesebut berarti tidak terdapat pengaruh yang signifikan antara persepsi staaf terkait manfaat SIM RSUD Kajen terhadap niat menggunakan SIM RSUD Kajen.

\section{Pengaruh Persepsi Kemudahan Penggunan terhadap Niat Menggunakan SIM RSUD Kajen}

Hasil uji $T$ persepsi kemudahan penggunan terhadap variabel niat menggunakan adalah sebesar 2,034 ( $\mathrm{T}>1,96)$, hal tesebut berarti terdapat pengaruh yang signifikan antara persepsi staff terkait kemudahan penggunaan terhadap niat menggunakan SIM RSUD Kajen. Semakin tinggi persepsi staff terkait kemudahan penggunaan SIM RSUD Kajen maka semakin tinggi pula niat staff untuk menggunakan SIM RSUD Kajen $(\mathrm{r}=0,463)$. Pengaruh Niat Menggunakan terhadap Perilaku Penggunaan SIM RSUD Kajen

Hasil uji $\mathrm{T}$ variabel niat menggunakan terhadap varibel perilaku penggunaan adalah sebesar $0,1201 \quad(\mathrm{~T}<1,96)$, hal tesebut berarti tidak terdapat pengaruh yang signifikan antara niat staff untuk menggunakan SIM RSUD Kajen terhadap perilaku penggunaan SIM RSUD Kajen.

\section{Pembahasan}

Kesesuaian sistem dengan pekerjaan tidak berpengaruh terhadap persepsi manfaat implementasi SIM RSUD Kajen. Kesesuaian pekerjaan merupakan faktor kognitif dalam diri individu yang dapat mempengaruhi persepsi seseorang dalam bekerja, namun pada penelitian ini tidak demikian. ${ }^{4}$ Hal tersebut terjadi karena dalam proses analisis kebutuhan SIM RSUD belum melibatkan seluruh pengguna sistem sehingga manfaat sistem kurang dapat dirasakan oleh pengguna sistem. Penelitian ini sejalan dengan penelitian yang dilakukan oleh Deydra dan Andeka dan penelitian yang dilakukan oleh Muhamad Rifqi. ${ }^{5,6}$

Norma subjektif tidak berpengaruh terhadap persepsi pengguna terkait manfaat SIM RSUD Kajen. Norma subjektif merupakan persepsi seseorang yang berkaitan dengan tekanan sosial, seseorang dengan tekanan sosial tinggi akan cenderung berperilaku sama dengan orang/kelompok yang mempengaruhinya. ${ }^{7}$ Pengalaman merupakan salah satu faktor yang berpengaruh terhadap persepsi seseorang terkait manfaat sistem informasi. $^{8}$ Berdasarkan pengertian tersebut dapat disimpulkan bahwa norma subjektif berpengaruh terhadap perilaku seseorang sedangkan persepsi seseorang dipengaruhi oleh pengalaman. Penelitian ini sejalan dengan penelitian yang dilakukan oleh Budiyanto pada tahun 2016 yang menyebutkan bahwa norma subjektif (SN) tidak berpengaruh terhadap persespi kemanfaatan (PU) pada penerimaan aplikasi dreamspark. ${ }^{9}$

Norma subjektif berpengaruh terhadap niat staff menggunakan SIM RSUD Kajen. Niat staff RSUD Kajen dalam menggunakan SIM RSUD Kajen 
dipengaruhi oleh dukungan dari lingkungan kerja dimana masukan, saran dan keputusan dari atasan serta teman kerja meningkatkan motivasi yang dapat memunculkan niat staff tersebut untuk berperilaku sama dengan memanfaatkan SIM RSUD Kajen dalam membantu tugas dan pekerjaannya. ${ }^{6}$ Hal tersebut sesuai dengan teori Chua bahwa teman, kolega dan kelompok orang yang potensial dapat mempengaruhi niat dan keinginan seseorang dalam menggunakan teknologi. ${ }^{10}$

Penelitian ini sejalan dengan penelitian yang dilakukan oleh Ika Puspaningtyas yang menyebutkan bahwa norma subjektif berpengaruh pada minat perilaku penggunaan sistem informasi akuntansi berbasis e-commerce. ${ }^{11}$

Keyakinan diri pengguna berpengaruh terhadap persepsi staff terkait kemudahan penggunaan SIM RSUD Kajen. Sumber utama keyakinan diri seseorang adalah persepsi baik fisik maupun emosional, seseorang dengan kepercayaan diri rendah akan merusak motivasi sehingga muncul anggapan dan perasaan bahwa seseorang tidak mampu menyelesaikan tugas dan pekerjannya. ${ }^{12}$ Kepercayaan diri seseorang dipengaruhi oleh pengetahuan dan keterampilan diri yang dapat diperoleh dari berbagai sumber seperti pelatihan. ${ }^{13}$ Penelitian ini sejalan dengan penelitian yang dilakukan oleh Park pada tahun 2009 dan Ni Luh Nyoman Sherina pada tahun 2014 yang menyatakan keyakinan diri pengguna berpengaruh terhadap niat menggunakan sistem informasi. ${ }^{14,15}$

Persepsi kemudahan penggunaan SIM RSUD Kajen berpengaruh terhadap persepsi staff terkait manfaat SIM RSUD Kajen. Semakin baik kemampuan staff dalam memahami sistem informasi maka semakin mudah pula staff tersebut menggunakan SIM RSUD Kajen secara efektif dan efisien. Kemudahan dalam menggunakan akan memunculkan persepsi staff dimana SIM RSUD Kajen memberikan manfaat dalam membantu tugas dan pekerjaan mereka. Persepsi kemudahan merupakan faktor determinan persepsi manfaat dimana staff akan lebih mudah memahami sistem informasi jika memiliki sikap dan pikiran postif terhadap sistem tersebut. ${ }^{16}$ Penelitian ini sejalan dengan penelitian yang dilakukan oleh Eki Saputra pada tahun 2014 dan penelitian yang dilakukan Muntianah pada tahun 2012. ${ }^{17,18}$

Persepsi terkait manfaat SIM RSUD Kajen tidak berpengaruh terhadap niat staff untuk menggunakan SIM RSUD Kajen. Davis menyatakan ketika seseorang merasakan manfaat teknologi informasi maka keinginan untuk menggunakan sistem tersebut meningkat. ${ }^{19}$ Penelitian ini tidak sejalan dengan teori tersebut, hal tersebut dikarenakan implementasi sistem informasi pada suatu organisasi berdampak pada perlunya staff untuk menyesuaikan dan beradaptasi dengan sistem yang baru, sehingga manfaat belum benar-benar dapat dirasakan. Penelitian ini sejalan dengan penelitian yang dilakukan Krismatya pada tahun 2015 dimana persepsi manfaat tidak berpengaruh pada niat menggunakan sistem pendaftaran online BPJS Kesehatan. ${ }^{14}$

Persepsi kemudahan penggunaan SIM RSUD Kajen berpengaruh terhadap niat staff menggunakan SIM RSUD kajen. Persepsi kemudahan penggunaan merupakan suatu kepercayaan yang berkaitan dengan proses pengambilan keputusan dalam menggunakan sistem informasi. Niat menggunakan akan muncul ketika seseorang merasa suatu sistem mudah digunakan, sederhana dan tidak 
membutuhkan banyak keterampilan. ${ }^{20}$ Penelitian ini sejalan dengan penelitian yang dilakukan David et,al. yang menyatakan kemudahan dalam memanfaatkan sistem informasi meningkatkan motivasi dan minat pengguna dalam menyelesaikan tugas dan pekerjaan mereka. $^{2}$

Niat menggunakan tidak berpengaruh terhadap perilaku penggunaan SIM RSUD Kajen. Perilaku penggunaan SIM RSUD Kajen merupakan intensitas penggunaan yang dipengaruhi oleh kesan terhadap sistem tersebut. Sistem akan digunakan ketika pengguna merasakan kemudahan dan manfaat serta adanya tekanan dari lingkungan sosialnya. ${ }^{21}$ Penelitian ini sejalan dengan penelitian yang dilakukan Deydra dan Andeka tahun 2015 bahwa niat menggunakan tidak berpengaruh pada perilaku penggunaan. ${ }^{3}$

\section{KESIMPULAN}

\begin{tabular}{llrr}
\multicolumn{2}{c}{ Penerimaan pengguna } & terkait \\
implementasi SIM & RSUD & Kajen
\end{tabular} Kabupaten Pekalongan dipengaruhi oleh variabel niat staff untuk menggunakan SIM RSUD Kajen. Niat staff untuk menggunakan SIM RSUD Kajen dipengaruhi secara langsung oleh norma subjektif $(T=3,275)$, persepsi staff terkait kemudahan penggunaan SIM RSUD Kajen $(\mathrm{T}=2,304)$ dan dipengaruhi secara tidak langsung oleh variabel kepercayaan diri pengguna $(T=7,857)$. Variabel persepsi kemudahaan penggunaan SIM RSUD Kajen berpengaruh secara langsung terhadap variabel persepsi staff terkait manfaat SIM RSUD Kajen Kabupaten Pekalongan $(\mathrm{T}=3,227)$.

\section{UCAPAN TERIMA KASIH}

Penulis mengucapkan terima kasih kepada RSUD Kajen Kabupaten Pekalongan.

\section{DAFTAR PUSTAKA}

4 . Venkatesh, V dan Davis, F.D. A Theoritical Extension of The Technology Acceptance Model: Four Longitudinal Field Studies. Management Science. 2000. 46 (2).

5 . Rehatta Deydra CZ, Tanaamah Andeka R. Evaluasi Penerimaan Pengguna terhadap Research Information System pada Universitas Kristen Satya Wacana menggunakan Technology Acceptance Model (TAM) 3. Salatiga: Universitas Kristen Satya Wacana; 2015.

6 . Setyadji Muhamad Rifqi, Iriawan Nur. Studi Empiris Penerimaan (U)JDIH di BPK RI Berbasis Technology Acceptance Model. Mataram: BPK RI Perwakilan NTB.

7 . Ajzen, I. Attitude, Personality and Behavior. New York: Open University Press; 2005.

8 . Bimo, Walgito. Pengantar Psikologi Umum. Jakarta: Andi; 2004.

9 . Prasetyo, Budiyanto. Pengukuran Penerimaan Aplikasi Dreamspark pada Stikom Surabaya menggunakan Metode Technology Acceptance Model 3 (TAM) Versi 3 (Skripsi). Surabya: Stikom Surabaya; 2016.

10 . Chua, EK. Consumer Intention to Deposit at Banks: An Empirical Investigation of Its Relationship With Attitude, Normative Belief and Confidence. Academic Exercise Faculty of Bussiness Administration; 1980.

11 . Puspaningtyas, Ika. Analisis FaktorFaktor yang Mempengaruhi Minat Perilaku terhadap Penggunaan Sistem Informasi Akuntansi Berbasis ECommerce. Surakarta: Fakultas Ekonomi dan Bisnis Universitas Muhammadiyah Surakarta; 2016. 
12 . Badura, A. Self Efficacy: Toward a Unifying Theory of Behavioral Change. Psychological Review. 64(2): 191-215.

13 . Dillon TW, Lending D, Crews TR, Balnkenship R. Nursing Self-Efficacy of An Integrated Clinical and Administrative Information System. Computers Informatics Nursing. 2003; 21(4):198-205.

14 . Park, S.Y. An Analysis of The Technology Acceptance Model in Understanding University Students Behavioral Intention To Use ELearning. Educational Technology \& Society. 2009; 12(3): 150-162.

15 . Devi NL Nyoman Sherina, Suartana I Wayan. Analisis Technology Acceptance Model (TAM) terhadap Penggunaan Sistem Informasi di Nusa Dua Beach Hotel \& Spa. E-Jurnal Akuntansi Universitas Udayana. 2014; 6(1): 167-184.

16 . Krismatya Prasastika, Winarno Wahyu Agus, Kartika. Pengujian Teori Technology Acceptance Model (TAM) untuk Memprediksi Penerimaan Sistem Pendaftaran Online BPJS Kesehatan Cabang Jember. Jember: Akuntansi Fakultas Ekonomu Unej. 2015.

17 . Saputra Eki, Misfariyan. Analisis Penerimaan Sistem Informasi Manajemen Rumah Sakit Umum Daerah Bangkinang Menggunakan Metode Technology Acceptance Model (TAM). Riau: Jurusan Sistem Informasi Fakultas Sains dan Teknologi Universitas Islam negeri Sultan Syarif Kasim Riau; 2014.

18 . Muntianah Siti Tutik, Astuti Endang Siti, Azizah Dewi Farah. Pengaruh Minat Perilaku terhadap Actual Use Teknologi Informasi dengan Pendekatan Technology Acceptance Model (TAM). Jurnal Profit. 2012. 6 (1).
19 . Davis, Gordon B. Sistem Informasi Manajemen. PT. Pustaka Binaman Pressindo; 1995.

20 . Chang Boon Patrick Lee dan Gouhua Wan. Including Subjective Norms and Technology Trust in The Technology Acceptance Model: A Case of E-Ticketing in China. The Data Base for Advances in Information Systems. 2015; 41 (2): 40-51.

21 . Sa'idah, Nurus. Analisis Penggunaan Sistem Pendaftaran Online (E-Health) berdasarkan Unified Theory of Acceptance and Use of Technology (UTAUT). Jurnal Administrasi Kesehatan Indonesia. 2017; 5(1). 